\title{
DA CABRÁLIA E SUAS CÓPULAS EM VERA CRUZ AO EFEITO BRASILIDADE
}

\section{Taciana de Melo Mafra ${ }^{(*)}$}

"Na língua verdadeiramente reside a nacionalidade" (Eça de Queirós, A correspondência de Fradique Mendes, p.142.)

Nossa brasilidade. Proponho articular a particularidade dessa posição diante da alteridade que a sustenta. De maneira especial, o lugar que legamos de nossos ancestrais portugueses, esses que nos impingem, cravam, instalam como sujeitos à língua portuguesa, a qual experimenta efeitos admiráveis nas permutas brasileiras.

Há quinhentos anos se escreveu nestas terras o primeiro registro português. Recebeu o estatuto de certidão de nascimento da extensa e bela nação do Novo Mundo, chamada pelo capitão da nau que a descobrira de Terra de Vera Cruz.

Suas linhas cunhavam letra a letra as impressões fascinadas de um português reverente, endereçando a sua majestade notícias da magnífica descoberta. Mais tarde, um hino faria soar outra versão, que numa estrofe rima a superioridade dos campos floridos e mananciais, dos bosques vívidos e dos fluidos de amores que nesta terra, desde sua primeira miragem, foram tidos como os maiores e mais ardentes.

O signatário do documento, tornado relíquia em suas vicissitudes, narra o estranho: "E dali avistamos homens que andavam pela praia, uns sete ou oito, segundo disseram os navios pequenos que chegaram primeiro. [...] Pardos, nus, sem coisa alguma que thes cobrisse suas vergonhas. Traziam arcos nas mãos, e suas setas".

Coisa curiosa o que se lê aí. Certamente que tal espanto também acometia os mirados nativos que num jogo de espelho

\footnotetext{
(") Analista, membro fundador do Toro de Psicanálise, autora de Um percurso em psicanálise com Lacan, A estrutura na obra lacaniana e A transferência (no prelo), todos pela editora Companhia de Freud, Rio de Janeiro.
} 
derrisível termina sendo encenado numa deliciosa minissérie que comemorou os 500 anos do Brasil.

Colonizadores e colonizados: foi assim que se consolidou a relação anunciada com tanta doçura por Pero Vaz de Caminha: "Entre todos estes que hoje vieram não veio mais que uma mulher, moça, a qual esteve sempre à missa, à qual deram um pano com que se cobrisse; e puseram-lho em volta dela. Todavia, ao sentar-se, não se lembrava de o estender muito para se cobrir. Assim. Senhor, a inocência desta gente é tal que a de Adão não seria maior, com respeito ao pudor". de Vera Cruz.

Desde esse primeiro registro tantos outros se fizeram na Terra

Os Jesuítas redigiram incontáveis textos informativos discorrendo sobre a natureza e os homens dessa terra. O Padre Manoel da Nóbrega nos dá um exemplo disso em seu "Diálogo para a conversão do gentio", onde exprime o drama da inconquistabilidade e a resistência à escravidão dos índios na Terra, agora, de Santa Cruz.

O desejo do colonizador de encontrar neste solo a riqueza e o espanto com os costumes silvícolas também foram retratados pelo tão conhecido Padre Anchieta, em seus "Autos pastoris". Bem e mal se reúnem, como sempre há de ser, e sob o eco de Virgílio irão se recombinar em métricas épicas, de simples beleza, em seus poemas.

Mas José de Anchieta também será autor de uma gramática tupi, curiosa empreitada para um missionário que procurava incutir os sentidos da língua latina nesses homens, que lhe pareciam estranhos por natureza. Nada natural. Falavam.

A retórica predominava, proezas da alteridade que exigiam persuasão e beleza.

Então, é a vez dos Sermōes. Padre António Vieira, arguto, prolixo defensor da abolição indígena e negra.

Gregório de Matos, em sua vez, cunha a brasilidade nas letras que redige. Desfrutando das particularidades da língua-mãe, sob os raios dos trópicos, onde diversas línguas deitam-se com sensualidade, fará embaraçosas combinações. Poesia lírica, sacra, profana e satírica, em estilo barroco acrescido de um tempero gongórico. Boca do Inferno. Assim foi chamado. Nada demoníaco. Poeta. Brasileiro, baiano, mais precisamente. 
Depois dele são mais 350 anos de um belíssimo português que não nega a cópula com outras línguas. O resultado é uma possibilidade ampla de dizeres, de metáforas ardentes, sofridas e alegres, mas com um resultado sempre surpreendente para o impasse e o nefasto.

O texto que se produziu, nesta terra de tantas diferenças, conta com as letras de Machado de Assis, que com seus contos nos permite outra metáfora para o espelho lacaniano; de Nelson Rodrigues, que nos lega, em verdadeiras tragédias modernas, novas metáforas edípicas; de Jorge Amado, que com tanto erotismo mescla irmandade do bem e do mal, do amor e do vício; de Carlos Drummont de Andrade, que maneja essa língua com uma delicadeza estonteante e palavreia as delícias das feridas d'alma; de Guimarães Rosa, que nos oferece enormes surpresas com a revelação dos efeitos de um nome e o deslizar fascinante da coragem e do temor; de Manoel de Barros, que, francamente, do des-saber inventa truques para fabricar brinquedos com palavras; brasileiras, é claro.

Ficaram tantos ausentes dessa pequena evocação, mas ausentes, portanto, inscritos na cadeia dessa língua da qual surgiu a tropicália, forma deliciosa de dialogar com outras línguas, pois é particularmente reverberante de humanidades, as mais diversas.

Que disso tenha decorrido tantos encontros e desencontros, sensualidade e atrocidades - verdadeiros dramas humanos -, só vem atualizar com brasilidade os episódios que ouvimos contar desde que o mundo é mundo e que os humanos habitam a Terra.

O Outro que colonizou este país consolida sua língua com a letra de Luís de Camões, a quem devemos reverência. "Os Lusíadas" exalta as façanhas dos lusitanos, mas também registra as agonias e amarguras do colonizador diante da conquista. Caetano cuidou dessa homenagem antes mesmo que chegassem os 500 anos: "Gosto de roçar a minha língua na língua de Luís de Camões".

Roçamos, copulamos, misturamos, diferenciamos. Invasão profícua essa de portugueses e nativos, invasão recíproca, a copor um povo tão espirituoso que, ao modo de Rabelais, no chiste, encontra tantas saídas para suas desventuras e desenganos.

Aliás, enveredando pela aproximação francesa, retomemos Lacan. Ele nos ensinou verdadeiros truques de grandes aproximações com o diferente, logros legítimos, embora isso pareça um paradoxo. 
Por isso foi acusado de plágio e por causa disso afirmou que no simbólico tudo não passa de plágio.

Retomamos a temática oswaldiana, a tão ousada antropofagia. Mas, não será preciso um manifesto, apenas rever um ensinamento de Lacan que provamos na carne.

Aproveito esta oportunidade para experimentar o tratamento de uma questão nuclear da teoria lacaniana, qual seja, a relação do sujeito ao Outro e seus desdobramentos.

Quem é esse Outro que odiamos e amamos? Concomitantemente, como se produz a dialética de uma invasão que é exigência para a estruturação na violência?

Permitam-me chover um pouco no molhado.

Para Lacan, se trata de estabelecer o caminho da questão no campo da linguagem. Aí estão os paradoxos com os quais lidamos todo dia em nossas clínicas, com as especificidades próprias a ela impostas pela estrutura.

Estamos diante da questão do significante em sua relação com a dialética do desejo, tal que se manifesta por sua propriedade permutativa remetendo-se um a outro e jamais apreendendo objeto algum.

Essa remetência tonifica, potencializa o desejo para o qual a única resposta possível é Outra questão, Che voi?

Tal questão estabelece de pronto o interlocutor diferenciado, um Outro que de maneira alguma poderia ser o semelhante.

$\mathrm{O}$ inconsciente, tal como Freud o concebe no "Projeto para uma psicologia científica", é uma concepção tópica, porém o lugar que revela é um lugar outro que não o de nossa conhecida relação com o mundo. Trata-se de um Outro lugar.

Contudo, situar o desejo no terreno da linguagem exige estabelecer uma demonstração, e isso Lacan efetiva demonstrando a estrutura da inscrição simbólica entre dois termos significantes S1 S2. O desejo é, propriamente, aquilo que faz passar ou tende a fazer passar do segundo significante para o primeiro.

Mas essa inscrição significante, essa representação, é movida pela tendência ao reencontro que está condenada a perder sempre. 
Uma lei como essa é, radicalmente, distinta de uma ética clássica do encontro com o objeto do Bem. Subordinar a ação humana à determinação do seu Bem, mesmo que apartando esse Bem (Gute) da experiência do prazer, como o faz a doutrina kantiana, é andar na contramão do verdadeiro Bem, no sentido da wunschvorstellung, da representação do desejo, em sua singularidade.

Freud afirmou, estrondosamente, que o sujeito não sabe o que faz quando fala e disso depreende-se que é impossível significar-se e significar a ação de significação. Lacan acresce: "Não existe inconsciente pelo fato de existir um desejo inconsciente, obtuso, pesado, canibal e até mesmo animal, desejo inconsciente saído das profundezas, que seria primitivo e que teria de elevar-se ao nível superior do consciente. Muito pelo contrário, existe desejo porque existe inconsciente, isto é, linguagem que escapa ao sujeito na estrutura e nos efeitos, e porque existe sempre algo no nível da linguagem que está além da consciência e é aí que se pode situar a função do desejo" .

Esse inconsciente, com Freud, sabemo-lo na fala, forjando continuamente mais um objeto. $\mathrm{O}$ nome o revela fundando as infindas combinações nas trocas simbólicas. Dessa forma, a Coisa da Psicanálise é corte com o Bem.

Lacan, ao percorrer o campo da Coisa afirmando sua impossibilidade, dirá que o Bem Supremo não existe, a mãe é proibida.

No entanto, é preciso livrar essa assertiva de qualquer psicologismo, como um desejo pela mãe. Lacan, ao contrário de Freud, dirá que a angústia não é angústia de separação, e sim, insuficiência de interdição, invasão do Outro.

O apelo à satisfação das necessidades vitais do homem é sempre endereçado a um Outro e, por isso mesmo, ganha um estatuto de demanda de amor.

Mas essa demanda jamais poderá ser atendida em absoluto, o que faz com que se sublinhe ou repita o que é perdido, na impossibilidade de haver uma ordem biológica que se baste a si mesma.

1 Safouan, M., citando Lacan, J. Psychanalyse et médecine. In: Lettres de l'école freudienne. n. 1, p.45. 
O Outro, portanto, seria o lugar de onde, na impossibilidade de responder simetricamente a uma demanda, estrutura-se a relação do sujeito com a linguagem.

Portanto, dizer que o "Eu é um Outro" aponta para o que está no cerne da constituição subjetiva, a saber, que a alteridade não é exterior à fronteira, a alteridade nos concerne na interioridade que funda o exterior.

De outro modo, poderíamos dizer que esse amor, do ponto em que é operação contígua entre desejo e demanda, estaria no cerne da formulação mítica onde se inaugura, diante de Outro, a subjetividade. Ou seja, se há sempre uma resposta constitutiva à demanda, podemos pensar que haverá sempre, nesse marco inaugural da relação com o Outro, algo que é da ordem do amor.

Mas esse amor constitutivo, que responde a essa demanda como um Dom, será sempre um equívoco enquanto que será sempre uma resposta construída a partir daquilo que falta a esse Outro colocado na posição de suposto detentor do que falta.

E está aí a possibilidade de escapar de uma alienação mortífera, posto que é na impossibilidade de uma coincidência do encontro do desejo e seu objeto que se fará simbólico e se desdobrará, infinitamente, a cadeia de significantes.

O amor, portanto, é esse ponto das operações subjetivas constitutivas do humano onde ele alcança a máxima hominização. É esse tecer possível da brecha dramática da condição do humano, mina da reconstrução.

A experiência analítica põe em curso a fala, onde se dão as comutações significantes capazes de ir além de uma relação de objeto, para encontrar um Outro Lugar de onde mina a linguagem. Aí está a singularidade da Psicanálise e o ponto onde ela marca a diferença de tudo o que a antecede.

O desejo é arredio a qualquer moral. Não há nada que possa domá-lo com imperativos categóricos. Estruturado com o Édipo, em Outro lugar, que não o da consciência, o desejo incestuoso, desejo pela mãe, é interditado pelo pai instaurando o simbólico.

A relação que instala a cadeia discursiva produzindo o sujeito da enunciação não é uma relação dual, mas sim uma relação na qual a língua responde à demanda com um Dom para além dela, a palavra. 
Pois bem, Lacan nos indica a faixa de Möebius, justamente para demonstrar que esse Outro não é exterior: "não há segurançaamor, porque isso seria segurança-ódio também. O amor-ódio é aquilo de que um psicanalista, mesmo não lacaniano, não reconhece senão a ambivalência, ou seja, a face única da faixa de Möebius"

Assim, retomamos o ponto inicial dessa comunicação, que se construiu pela tentação de compor um texto recolocando, neste ano, as operações subjetivas em torno do mito da colonização brasileira, no que concerne a nossa posição de "novo mundo", S2.

Esse Outro caraíba, português, que vem supostamente lograr nossos tesouros, àqueles, relativos aos bens, objetos fálicos por excelência, antes de tudo é arca significante, nossa língua. sua fala?

Que saber uma tal posição articula? E que verdade enuncia

A alteridade, que produz o sujeito da brasilidade, é fundamentalmente aquela que concerne ao código de suas representações, à legalidade da língua; e esse sujeito como tal é um efeito da pontuação da sintaxe que, a partir da língua, se produz. A alteridade é, portanto, destituída de um lugar topológico da ordem de uma fronteira que comporte uma exterioridade personificada.

O colonizador, encarnado e afetado pela relação de amor e ódio, é um efeito imaginário da trama subjetiva na qual ele vale pelo símbolo que é. Daí advém a relação do sujeito a esse Outro, a dimensão do mais íntimo.

Chegamos ao confronto com a trama da identidade e ouvimos então o eco de Freud a dizer-nos: "A história das origens e relações do amor nos permite compreender como é que o amor com tanta freqüencia se manifesta como 'ambivalente' - isto é, acompanhado de impulsos de ódio contra o mesmo objeto. O ódio que se mescla ao amor provém em parte das fases preliminares do amar não inteiramente superadas; baseia-se também em parte nas reações de repúdio aos instintos do ego, os quais, em vista dos frequentes conflitos entre os interesses do ego e os do amor, podem encontrar fundamentos em motivos reais e contemporâneos. Em ambos os casos, portanto, o ódio mesclado tem como sua fonte os instintos

2 Lacan, J. L'Etourdit. Inédito. 
autopreservativos. Se uma relação de amor com um dado objeto for rompida, freqüentemente o ódio surgirá em seu lugar, de modo que temos a impressão de uma transformação do amor em ódio. Esse relato do que acontece leva ao conceito de que o ódio, que tem seus motivos reais, é aqui reforçado por uma regressão do amor à fase preliminar sádica, de modo que o ódio adquire um caráter erótico, ficando assegurada a continuidade de uma relação de amor." de Camões:

Cuidemos de celebrar a alteridade com um poema de Luís Vaz

Transforma-se o amador na coisa amada, Por virtude do muito imaginar;

Não tenho logo mais que desejar,

Pois em mim tenho a parte desejada.

Se nela está minha alma transformada, Que mais deseja o corpo de alcançar?

Em si somente pode descansar,

Pois consigo tal alma está ligada.

Mas esta linda e pura semidéia, Que, como o acidente em seu sujeito, Assim como a alma minha se conforma,

Está no pensamento como idéia;

O vivo e puro amor de que sou feito, Como a matéria simples busca a forma.

3 Freud, S. (1976[1914-1916) Os Instintos e suas vicissitudes. Edição Standard Brasileira das Obras Completas de Sigmund Freud. Vol.XIV. Rio de Janeiro; Imago, p.161. 


\section{REFERÊNCIAS BIBLIOGRÁFICAS}

FREUD, S. (1914-1916) Os Instintos e suas vicissitudes. Edição Standard Brasileira das Obras Completas de Sigmund Freud. Vol.XIV. Rio de Janeiro: Imago, 1976, p.161.

FREUD, S. (1895) Projeto para uam psicologia científica. Edição Standard Brasileira das Obras Completas de Sigmund Freud. Vol. I. Rio de Janeiro: Imago, 1977.

LACAN, J. (1960) O livro 7 - A ética da psicanálise. Rio de Janeiro: Zahar, 1986.

LACAN, J. L'etourdit. Inédito.[sl.,sd.]

QUEIROZ, E. A correspondência de Fradique Mendes. Lisboa: Livraria Lello \& Irmão Editores, 1946.

SAFOUAN, M., citando Lacan, J. Psychanalyse et médecine. In: Lettres de l'école freudienne. n.1, p.45.

SOUTO, M. A História do Brasil. São Paulo: Companhia Editora Nacional, 1967.

SERMÕES, A. Sermões. São Paulo: Cultrix, 1995. 